\title{
Reference equations for the six-minute walk distance based on a Brazilian multicenter study
}

\author{
Raquel R. Britto ${ }^{1}$, Vanessa S. Probst ${ }^{2,3}$, \\ Armele F. Dornelas de Andrade ${ }^{4}$, Giane A. R. Samora ${ }^{1}$, \\ Nidia A. Hernandes ${ }^{2,3}$, Patrícia E. M. Marinho ${ }^{4}$, \\ Marlus Karsten ${ }^{5}$, Fabio Pitta ${ }^{2}$, Veronica F. Parreira ${ }^{1}$
}

\begin{abstract}
Background: It is important to include large sample sizes and different factors that influence the sixminute walking distance (6MWD) in order to propose reference equations for the six-minute walking test (6MWT). Objective: To evaluate the influence of anthropometric, demographic, and physiologic variables on the 6MWD of healthy subjects from different regions of Brazil to establish a reference equation for the Brazilian population. Method: In a multicenter study, 617 healthy subjects performed two 6MWTs and had their weight, height, and body mass index (BMI) measured, as well as their physiologic responses to the test. Delta heart rate ( $\Delta \mathrm{HR})$, perceived effort, and peripheral oxygen saturation were calculated by the difference between the respective values at the end of the test minus the baseline value. Results: Walking distance averaged $586 \pm 106 \mathrm{~m}, 54 \mathrm{~m}$ greater in male compared to female subjects $(\mathrm{p}<0.001)$. No differences were observed among the $6 \mathrm{MWD}$ from different regions. The quadratic regression analysis considering only anthropometric and demographic data explained $46 \%$ of the variability in the $6 \mathrm{MWT}(\mathrm{p}<0.001)$ and derived the equation: $6 \mathrm{MWD}_{\text {pred }}=890.46-(6.11 \times$ age $)+\left(0.0345 \times\right.$ age $\left.^{2}\right)+(48.87 \times$ gender $)-(4.87 \times \mathrm{BMI})$. A second model of stepwise multiple regression including $\Delta \mathrm{HR}$ explained $62 \%$ of the variability $(\mathrm{p}<0.0001)$ and derived the equation: $6 \mathrm{MWD}_{\text {pred }}=356.658-(2.303 \times$ age $)+(36.648 \times$ gender $)+(1.704 \times$ height $)+(1.365 \times \Delta \mathrm{HR})$. Conclusion: The equations proposed in this study, especially the second one, seem adequate to accurately predict the 6MWD for Brazilians.
\end{abstract}

Keywords: walking; exercise test; reference values; regression analysis; rehabilitation.

\section{HOW TO CITE THIS ARTICLE}

Britto RR, Probst VS, Dornelas de Andrade AF, Samora GAR, Hernandes NA, Marinho PEM et al. Reference equations for the six-minute walk distance based on a Brazilian multicenter study. Braz J Phys Ther. 2013 Nov-Dec; 17(6):556-563. http://dx.doi. org/10.1590/S1413-35552012005000122

\section{Introduction}

The ability to walk a distance is an easy and inexpensive way to assess physical capacity in health and illness. Among the field tests proposed in the literature, the 6-minute walk test (6MWT) has been widely used to assess the functional exercise capacity of patients with limiting conditions such as cardiopulmonary diseases ${ }^{1}$. The test is simple, safe and provides a global and integrated response of all systems involved during exercise based on the distance walked in a level corridor during 6 minutes $(6 \mathrm{MWD})^{1,2}$. The 6MWT has a submaximal design $^{2}$ and, because most activities of daily living are performed at submaximal levels, it is a good reflection of the functional exercise level for daily physical activities ${ }^{1,3}$. The distance covered during the test has been used to assess response to therapeutic interventions (pharmacological and nonpharmacological) ${ }^{4}$ to detect exertional desaturation and need of long-term oxygen therapy ${ }^{5}$ and to predict morbimortality in cardiopulmonary diseases ${ }^{6-8}$.

According to the guidelines of the American Thoracic Society (ATS) ${ }^{1}$, the interpretation of the 6MWT should ideally be done by considering age, height, weight, and gender, variables which independently affect the 6MWT in healthy adults. Thus, equations for predicting reference values of the 6MWT are necessary. In fact, some reference equations have been proposed previously for people from different countries, including Brazilian samples $^{2,9-17}$. However, aspects that needed to be better

\footnotetext{
${ }^{1}$ Laboratory for Assessment and Research in Cardiorespiratory Performance, Physical Therapy Department, Universidade Federal de Minas Gerais (UFMG), Belo Horizonte, MG, Brazil

${ }^{2}$ Pulmonary Physical Therapy Research Laboratory (LFIP), Physical Therapy Department, Universidade Estadual de Londrina (UEL), Londrina, PR, Brazil

${ }^{3}$ Health Sciences Research Center, Universidade Norte do Paraná (UNOPAR), Londrina, PR, Brazil

${ }^{4}$ Cardiopulmonary Physiology and Physical Therapy Laboratory, Physical Therapy Department, Universidade Federal de Pernambuco (UFPE), Recife, PE, Brazil

${ }^{5}$ Graduate Program in Rehabilitation Sciences, Universidade Federal de Ciências da Saúde de Porto Alegre (UFCSPA), Porto Alegre, RS, Brazil Received: 11/22/2012 Revised: 04/29/2013 Accepted: 06/07/2013
} 
considered in future studies were identified ${ }^{11,12,16,18}$. Firstly, it is essential that new studies be performed with larger sample sizes ${ }^{11,16,18}$. Secondly, since the age range is limited in some of the studies ${ }^{2,13,17}$, not all equations are applicable to young people. Finally, although the interference of physiologic variables (e.g., heart rate) in the 6MWD has been suggested and considered important ${ }^{12,13,18}$, few studies have considered these variables in reference equations.

Given that Brazil is a large country with different climates and diverse socioeconomic and cultural conditions, a multicenter study that can provide samples from different regions of the country is vital to establishing a more representative reference equation for the $6 \mathrm{MWT}^{18}$. Therefore, taking into consideration the importance of the 6MWT in clinical and research settings, by circumventing some of the current limitations, we aimed to study the influence of anthropometric, demographic, and physiologic variables on the 6MWT of a large, multicenter sample of healthy Brazilian subjects and to establish an equation for predicting reference values of the 6MWT for the Brazilian population.

\section{Method}

\section{Subjects}

In the present multicenter study, although a sample size of 328 subjects was calculated to consider four variables in the regression model, 629 healthy subjects from four centers located in the Northeastern (1), Southeastern (2), and Southern (1) regions of Brazil were included. They were recruited from the local community and among students and employees of four universities, as well as their relatives. All of them had their anthropometric and demographic characteristics assessed and performed two 6MWTs. Data were collected from July 2008 to July 2011. The study was approved by the Research Ethics Committee of Universidade Federal de Minas Gerais (UFMG), Belo Horizonte, MG, Brazil (ETIC approval number 390-04). All participants gave written informed consent.

The inclusion criteria were: subjects of both genders aged 18 years or more; ability to understand and perform all procedures proposed; absence of any severe and/or unstable disease which could limit exercise tolerance, such as chronic obstructive pulmonary disease, asthma, cystic fibrosis, interstitial lung disease, angina, myocardial infarction, congestive heart failure, stroke, transient ischemic attack, peripheral vascular disease, and arthritis ${ }^{19}$. Subjects were excluded if they had a body mass index (BMI) under $18 \mathrm{~kg} \cdot \mathrm{m}^{-2}$ and above
$40 \mathrm{~kg} \cdot \mathrm{m}^{-2}$ or if they could not perform two 6MWTs for any reason.

\section{6-minute walk test}

In all centers, subjects performed two 6MWTs according to the ATS standardized protocol ${ }^{1}$ with, at least, $30 \mathrm{~min}$ of rest between them. The test was performed in a 30-m corridor, and the subjects were instructed to keep walking for 6 minutes. The best walked distance was considered for analysis. The tests were applied by a physical therapist or previously trained physical therapy student, and both 6MWTs were applied by the same assessor. Blood pressure, heart rate (HR), peripheral oxygen saturation $\left(\mathrm{SpO}_{2}\right)$, and perceived dyspnea and leg fatigue (modified Borg scale $)^{20}$ were assessed before and immediately after the tests. During the tests, $\mathrm{HR}$ and $\mathrm{SpO}_{2}$ were continuously verified and standardized phrases of encouragement were spoken to the participants every minute ${ }^{1}$ (ATS, 2002). The predicted maximal HR (HRmax) was derived from the formula HRmax $=220-$ age $^{21}$. The delta of HR $(\Delta H R)$, perceived effort ( $\Delta$ Borg), and $\mathrm{SpO}_{2}\left(\Delta \mathrm{SpO}_{2}\right)$ were calculated by the difference between the respective value at the end of the test minus the baseline value.

\section{Anthropometric and demographic data and health status}

A questionnaire was applied in order to investigate the health status of the participants. Height $(\mathrm{cm})$ and body weight $(\mathrm{Kg})$ were measured, and the BMI was calculated.

\section{Statistical analysis}

The statistical analysis was performed using the statistical packages SPSS 17.0 (SPSS Inc., USA) and STATA 12.0 (STATA Corp, USA). The normality of data distribution was evaluated using the Kolmogorov-Smirnov test. The Mann-Whitney test or the independent Student t test was used to compare male and female characteristics. The comparisons between regions were assessed using the Kruskall-Wallis test followed by post-hoc MannWhitney, when appropriate. Spearman's correlation coefficient was used to verify the simple correlation between the walked distance (dependent variable) and age, gender, weight, height, $\mathrm{BMI}, \mathrm{SpO}_{2}, \mathrm{HRmax}$ $\%$ predicted, and $\Delta \mathrm{HR}$. Two regression models were applied to derive reference equations both considering the association between the variables and the distance walked in the 6MWT. The best models were constructed considering the variables with the 
best independent coefficient of determination $\left(\mathrm{R}^{2}\right)$ and statistical significance as $\mathrm{p}<0.05$. The first model included only demographic and anthropometric variables as independent variables (age, gender, weight, height, and BMI). In a stepwise multiple linear regression model, the assumptions of normality of the residuals score were not met, so a quadratic regression model (Equation 1) was used. The second model, a stepwise multiple linear regression model, included the same independent variables used in the first model in addition to physiologic variables $\left(\mathrm{SpO}_{2}, \mathrm{HRmax} \%\right.$ predicted, $\left.\Delta \mathrm{HR}\right)$ and the normality of the residuals score was met (Equation 2). Since equation 2 showed a much higher coefficient of determination (see results), further analysis focused on this specific equation. In order to verify the reliability of Equation 2, it was applied a posteriori analysis in a different group of healthy subjects, composed of 58 individuals selected according to the same inclusion criteria in the different centers. In addition, Equation 2 was cross-validated against prediction equations existing in the literature in this group, considering only the subjects with the same age range of each study. The level of statistical significance was considered as $\mathrm{p}<0.05$.

\section{Results}

From the 629 healthy subjects selected, 12 (2\%) were excluded and 617 were included in the final analysis. The subjects were aged 19 to 79 years and $52 \%$ were women. Table 1 shows descriptive data on characteristics of the studied subjects and outcome parameters of the best 6MWT. The participants were distributed by age range as follows: 19-29 years $(\mathrm{n}=155)$; 30-39 years $(\mathrm{n}=66) ; 40-49$ years $(\mathrm{n}=77)$; $50-59$ years $(n=83) ; 60-69$ years $(n=110)$, and $70-79$ years $(n=126)$. According to the BMI classification of body composition $\left(\mathrm{kg} / \mathrm{m}^{2}\right), 47.1 \%$ were normal (18.5 to 24.9 ), $37.9 \%$ were overweight (25.0 to 29.9), and $14.9 \%$ were obese (30.0 to 39.9).

\section{Comparison between regions}

Table 2 shows that, despite the differences in anthropometric parameters observed among the 3 different regions, the 6MWD was similar.

\section{MWT determinants and reference equations}

There were significant correlations between the walked distance and age $(\mathrm{r}=0.55, \mathrm{p}<0.0001)$, height $(\mathrm{r}=0.48, \mathrm{p}<0.0001)$, BMI $(\mathrm{r}=0.40, \mathrm{p}<0.0001)$, and $\Delta \mathrm{HR}(\mathrm{r}=0.43, \mathrm{p}<0.0001)$. A model of quadratic regression analysis showed that age, gender, and BMI explained $46 \%$ of the variability in the 6MWT $\left(\mathrm{R}^{2}=0.46, \mathrm{p}<0.0001\right.$; Table 3$)$. The derived equation (Equation 1) for the 6MWT based on this analysis considering only anthropometric and demographic data was:

$$
\begin{aligned}
6 \mathrm{MWD}_{\text {pred }} & =890.46-(6.11 \times \text { age })+\left(0.0345 \times \mathrm{age}^{2}\right)+ \\
& (48.87 \times \text { gender })-(4.87 \times \mathrm{BMI})
\end{aligned}
$$

(where male gender $=1$ and female gender $=0$ ).

\begin{tabular}{|c|c|c|c|c|}
\hline & Total $(n=617)$ & Male (n=296) & Female $(n=321)$ & p-values* \\
\hline Age (years) & $52(29-67)$ & $49(27-68)$ & $53(31-67)$ & 0.509 \\
\hline Height (cm) & $164(157-171)$ & $170(166-176)$ & $158(152-163)$ & $<0.0001$ \\
\hline Weight (kg) & $68(59-78)$ & $74(66-81)$ & $62(55-71)$ & $<0.0001$ \\
\hline BMI $\left(\mathrm{kg} \cdot \mathrm{m}^{-2}\right)$ & $25(23-28)$ & $25(23-28)$ & $25(22-28)$ & 0.210 \\
\hline 6MWD (m) & $586 \pm 106$ & $614 \pm 102$ & $560 \pm 103$ & $<0.0001$ \\
\hline $\mathrm{HR}_{\text {baseline }}(\mathrm{bpm})$ & $82(73-91)$ & $80(71-90)$ & $83(75-92)$ & 0.036 \\
\hline$\Delta \mathrm{HR}(\mathrm{bpm})$ & $41(25-59)$ & $41(25-60)$ & $41(25-58)$ & 0.925 \\
\hline$\%$ HRmax & $73(64-83)$ & $73(64-82)$ & $74(65-84)$ & 0.321 \\
\hline $\mathrm{SpO}_{2 \text { baseline }}(\%)$ & 97 (96-98) & $97(95-98)$ & 97 (96-98) & 0.957 \\
\hline$\Delta \mathrm{SpO}_{2}(\%)$ & $0(-2$ to -1$)$ & $0(-1$ to 1$)$ & $0(-2$ to -1$)$ & 0.825 \\
\hline Borg $F_{\text {baseline }}(p t s)$ & $0(0-0)$ & $0(0-0)$ & $0(0-0)$ & 0.053 \\
\hline$\Delta$ Borg F (pts) & $1.5(0.5-2.5)$ & $1(0.3-2.0)$ & $1.5(0.5-3.0)$ & 0.020 \\
\hline
\end{tabular}

Table 1. Characteristics of the subjects and outcome parameters of the best 6MWT.

Data are expressed as median (interquartile range 25\%-75\%) except for the 6MWD (mean and SD). BMI: body mass index; 6MWT: 6-minute walk test; HR: heart rate, \%HRmax: \% of the maximal predicted heart rate; $\mathrm{SpO}_{2}$ : peripheral oxygen saturation; Borg F: perceived leg fatigue assessed by the Borg scale. *Comparisons between male and female using the Mann-Whitney test. 
Table 2. Anthropometric characteristics and 6MWD values from the three regions.

\begin{tabular}{|c|c|c|c|c|}
\hline & Southeast $(n=194)$ & South $(n=271)$ & Northeast $(n=152)$ & p value ${ }^{\#}$ \\
\hline Age (years) & $47.00(33.0-67.00)$ & $58.00 *(37.00-69.00)$ & $35.50 * \dagger(22.00-57.00)$ & $<0.001$ \\
\hline Height (cm) & $166.00(158.75-172.00)$ & $167.00(157.00-174.00)$ & $160.50^{*} \dagger(154.25-165.75)$ & $<0.001$ \\
\hline Weight (kg) & $69.95(62.00-79.28)$ & $71.00(63.00-79.20)$ & $59.90^{*} \dagger(55.00-68.81)$ & $<0.001$ \\
\hline BMI $\left(\mathrm{kg} \cdot \mathrm{m}^{-2}\right)$ & $25.48(23.08-28.13)$ & $25.59(23.39-27.97)$ & $23.46^{* \dagger}+(21.01-27.23)$ & $<0.001$ \\
\hline 6MWD (m) & $570.00(515.75-642.00)$ & $581.00(512.00-658.00)$ & $598.00^{*}+(477.13-664.50)$ & 0.457 \\
\hline
\end{tabular}

Data are expressed as median (interquartile range 25\%-75\%). ${ }^{*}$ Kruskal-Wallis Test. ${ }^{*} \mathrm{p}<0.01$ compared to Southeast; $\dagger \mathrm{p}<0.01$ compared to South. Post hoc Mann-Whitney test. 6MWD= six minute walking distance.

Table 3. Quadratic regression with the 6MWD as dependent variable considering only demographic variables (Equation 1).

\begin{tabular}{|c|c|c|c|c|}
\hline & $\begin{array}{l}\text { Non-standardized } \\
\text { coefficients }(B)\end{array}$ & $\begin{array}{l}\text { 95\% Confidence } \\
\text { interval for B }\end{array}$ & p-value & Partial R $^{2}(\%)$ \\
\hline Constant & 890.46 & $840.35-940.57$ & $<0.001$ & \\
\hline Age (years) & -6.11 & $-8.35--3.88$ & $<0.001$ & 21.20 \\
\hline $\mathrm{Age}^{2}$ (years) & 0.0345 & $0.0117-0.0573$ & 0.003 & 11.90 \\
\hline Gender* & 48.87 & $36.6-61.14$ & $<0.001$ & 30.10 \\
\hline BMI $\left(\mathrm{kg} \cdot \mathrm{m}^{-2}\right)$ & -4.87 & $-6.46--3.28$ & $<0.001$ & 23.60 \\
\hline
\end{tabular}

Standard error of the estimate $=77.2 \mathrm{~m}$. BMI=body mass index; The derived equation for the 6MWD predicted based on the quadratic regression analysis was: $6 \mathrm{MWD}=890.46-(6.11 \times$ age $)+\left(0.0345 \times \mathrm{age}^{2}\right)+(48.87 \times$ gender $)-(4.87 \times \mathrm{BMI}) ; *$ Male gender $=1$ and female gender $=0.95 \% \mathrm{CI}$ $=95 \%$ confidence interval for the coefficient.

The second model of stepwise multiple regression showed that age, gender, height, and $\Delta \mathrm{HR}$ explained $62 \%\left(\mathrm{R}^{2}=0.616, \mathrm{p}<0.0001\right)$ of the variability in the $6 \mathrm{MWT}$ (Table 4). The derived equation (Equation 2) for the distance walked in the 6MWT was:

$$
\begin{aligned}
& 6 \mathrm{MWD}_{\text {pred }}=356.658-(2.303 \times \text { age })+(36.648 \times \text { gender })+ \\
&(1.704 \times \text { height })+(1.365 \times \Delta \mathrm{HR})
\end{aligned}
$$

(where male gender $=1$ and female gender $=0$ ).

\section{Reliability of equation 2 and comparison with other reference equations}

The characteristics of the other group composed of 58 healthy subjects ( 23 male and 35 female) included in the a posteriori analysis were: age $52 \pm 15$ years and BMI $26 \pm 4 \mathrm{~kg} / \mathrm{m}^{2}$. When equation 2 was applied in this group, there was no difference between the actual and the predicted 6MWD (565 m vs. $582 \mathrm{~m}$, $\mathrm{p}=0.11$, respectively) with a significant correlation between them $(r=0.76, p<0.0001)$.

When previous reference equations published in the literature were applied in the a posteriori analysis, positive and significant correlations with the walked distance by the 58 subjects were observed (Table 5). The comparison indicated differences in four of them ${ }^{2,10,11,17}$.

\section{Discussion}

This study presented new equations to predict the distance covered during the 6MWT in Brazilian subjects and showed that approximately $62 \%$ of the variance was explained by gender, age, height, and the change in heart rate $(\Delta \mathrm{HR})$ during the test. When no physiologic variables were entered into the logistic analysis, approximately $47 \%$ of the variance was explained by the combination of gender, age, age $^{2}$, and BMI.

The present study has two strong methodological characteristics. Firstly, to the best of our knowledge, this is the study with the largest sample to propose a reference equation for the 6MWT in this population. Secondly, this study had a multicenter design and was therefore the first to have a sample composed of subjects from three regions of the country.

The sample was well distributed according to age, considering the classification of the American College of Sports Medicine ${ }^{22}$, with 221 (35.8\%) young (<39yr), 200 (32.4\%) middle-aged (40-64yr), and $196(31.8 \%)$ elderly (65-79yr) subjects. The number of overweight and obese subjects (levels I and II) is similar to the one identified in the Brazilian population ${ }^{23}$. Thus, the sample reflects the characteristics and variations as they exist in the real 
Table 4. Multiple linear stepwise regression analysis with the 6MWD as dependent variable considering demographic variables and delta heart rate (Equation 2).

\begin{tabular}{|c|c|c|c|c|}
\hline & $\begin{array}{l}\text { Non-standardized } \\
\text { coefficients (B) }\end{array}$ & $\begin{array}{l}\text { 95\% Confidence } \\
\text { interval for B }\end{array}$ & p-value & Partial R $^{2}(\%)$ \\
\hline Constant & 356.658 & 209.36-503.96 & $<0.0001$ & \\
\hline Age (years) & -2.303 & $21.07-52.23$ & $<0.0001$ & 47.90 \\
\hline Gender* & 36.648 & $1.11-1.63$ & $<0.0001$ & 19.50 \\
\hline Height $(\mathrm{cm})$ & 1.704 & $-2.66--1.95$ & $<0.0001$ & 16.50 \\
\hline$\Delta \mathrm{HR}$ & 1.365 & $0.84-2.57$ & $<0.0001$ & 40.60 \\
\hline
\end{tabular}

Standard error of the estimate $=64.3 \mathrm{~m}$. The derived equation for the $6 \mathrm{MWD}$ based on the regression analysis was: $6 \mathrm{MWD}_{\text {pred }}=356.658-$ $(2.303 \times$ age $)+(36.648 \times$ gender $)+(1.704 \times$ height $)+(1.365 \times \Delta$ HR $) . *$ Male gender $=1$ and female gender $=0$.

Table 5. Comparison and correlation between the actual walked distance in the a posteriori group ( $\mathrm{n}=58)$ (median 565 meters) and the predicted distance by other previously published equations.

\begin{tabular}{|c|c|c|c|}
\hline $\begin{array}{c}\text { Equation/age range } \\
\text { (years) }\end{array}$ & $\begin{array}{l}\text { Number of pairs } \\
\text { with similar age }\end{array}$ & $\begin{array}{l}\text { Predicted distance } \\
\text { (m) }\end{array}$ & $\begin{array}{c}\text { Spearman Correlation } \\
\text { (rho; p-value) }\end{array}$ \\
\hline \multicolumn{4}{|l|}{$\begin{array}{l}\text { Enright and Sherrill }{ }^{9} \\
\quad 40-80\end{array}$} \\
\hline Male $(n=117)$ & 18 & $555(411-654)$ & $0.63 ; 0.005$ \\
\hline Female $(n=173)$ & 31 & $518(367-642)$ & $0.39 ; 0.028$ \\
\hline \multicolumn{4}{|l|}{ Troosters et al. ${ }^{2}$} \\
\hline $50-85(n=31)$ & 35 & $606(431-747)^{*}$ & $0.57 ;<0.0001$ \\
\hline \multicolumn{4}{|l|}{ Gibbons et al. ${ }^{10}$} \\
\hline $20-80(n=79)$ & 58 & $667(558-803)^{*}$ & $0.63 ;<0.0001$ \\
\hline \multicolumn{4}{|l|}{ Chetta et al. ${ }^{13}$} \\
\hline $20-50(n=102)$ & 25 & $597(530-680)$ & $0.53 ; 0.006$ \\
\hline \multicolumn{4}{|l|}{ Camarri et al. ${ }^{11}$} \\
\hline $55-75(n=22)$ & 21 & $661(601-746)^{*}$ & $0.58 ; 0.006$ \\
\hline \multicolumn{4}{|l|}{ Iwama et al. ${ }^{16}$} \\
\hline $13-84(n=134)$ & 58 & $550(477-643)$ & $0.59 ;<0.0001$ \\
\hline \multicolumn{4}{|l|}{ Dourado et al. ${ }^{17}$} \\
\hline$\geq 40(n=90)$ & 49 & $598(464-688)^{*}$ & $0.48 ;<0.0001$ \\
\hline \multicolumn{4}{|l|}{ Soares and Pereira ${ }^{15}$} \\
\hline $20-80(n=132)$ & 58 & $550(398-661)$ & $0.71 ;<0.0001$ \\
\hline
\end{tabular}

Data expressed as median (minimum-maximum). $* \mathrm{p}<0.0001$ compared with the walked distance of the 58 individuals=565 $\mathrm{m}(352-870)$. Mann-Whitney Test.

population, increasing the external validity. Previous studies have reported the influence of age $\mathrm{e}^{11,20,24}$ and BMI on the $6 \mathrm{MWD}^{11,16,24}$.

The results indicated differences between the anthropometric characteristics of subjects from different regions. However, it was not sufficient to produce differences in walking distance when the three regions were compared. Region-to-region difference occurred when comparing the Northeast to the other two regions, although this difference was probably due to the younger age of this specific subgroup. Taking into consideration the absence of differences (Table 4), this indicates the possibility of generalizing the 6MWD reference equations for all Brazilian regions, at least in studies where a large age-range is considered ${ }^{15,16}$.

The influence of the relative intensity of the test represented by the $\Delta \mathrm{HR}$ was identified as an important variable with $41 \%$ of partial correlation in Equation 2. The study by Chetta et al. ${ }^{13}$ mentioned 
the importance of considering the heart rate during the 6MWT, however this variable was not included in the reference equation proposed by those authors. Poh et al. ${ }^{12}$ considered the $\%$ of predicted HRmax in the equation as well as age, height, and weight and explained $78 \%$ of the variance of the $6 \mathrm{MWD}$, despite the small sample size $(n=35)$. The authors considered that the use of the $\%$ of predicted HRmax in the equation may be limited when measuring the 6MWD in subjects with diseases or medications which have an influence on HRmax. However, the use of the change in HR during the test $(\Delta \mathrm{HR})$ could, at least in part, counteract this limitation. This may happen since these diseases and medications interfere not only in the HR at the end of the test but also in the resting HR, and therefore their influence on this specific outcome $(\Delta \mathrm{HR})$ may be counterbalanced and reduced.

A recent international multicenter study evaluated the geographic variations of the 6MWD in a cohort of healthy adults and suggested that the resulting distance could be influenced by factors such as the speed of habitual walking and other aspects related to lifestyle such as the motivation of the subject and/ or the assessor ${ }^{25}$. These aspects were not evaluated in the present study, however they could influence the $\Delta \mathrm{HR}$. As the 6MWT is self-paced, the use of the $\Delta \mathrm{HR}$ considers the freedom of the subjects to choose the speed, despite the standardized instructions and encouragement. Furthermore, the influence of encouragement on the subject's performance has been discussed since 1984 by Guyatt et al. ${ }^{26}$, and the ATS Guidelines (2002) ${ }^{1}$ consider it an important determinant of the distance covered in the 6MWT. Nevertheless, motivation involves two aspects: extrinsic and intrinsic motivation ${ }^{27}$. Standardizing motivation phrases is a way to control the extrinsic factor, which produces different responses in subjects depending on their intrinsic motivation. The $\Delta \mathrm{HR}$ could indicate how the subjects respond to the extrinsic motivation during the 6MWT. This selfdetermination theory has been used to evaluate the response of changes in exercise training behavior ${ }^{26}$ but has not been evaluated in self-regulated exercise tests. All of these factors help to explain, at least in part, the positive role of including $\Delta \mathrm{HR}$ in the prediction of the 6MWD's normal values. Recently, the use of rest HR was considered to predict maximal oxygen consumption based on the 6MWT ${ }^{28}$.

Equation 1, which considered only anthropometric and demographic variables, explained almost half of the variance in the 6MWT. This showed that age, gender, and BMI are important to predict the 6MWD in agreement with the vast majority of the studies designed to propose reference equations for this test. It is, therefore, an option to be used in case it is not possible to obtain the $\Delta \mathrm{HR}$ and use Equation 2.

The comparison with other studies allowed us to identify that the equations proposed by Troosters et al. ${ }^{2}$, Gibbons et al. ${ }^{10}$, Camarri et al. ${ }^{11}$, and Dourado et al. ${ }^{17}$ predicted 6MWD with a statistical difference in comparison to the distance observed in the present study. These discrepancies could be related to differences in the test protocol, encouragement, and different aspects of motivation, as previously discussed. Sample size $e^{2,3,10,17}$, combined with different characteristics of each population ${ }^{2,3,10}$, could also contribute to this discrepancy. The equation proposed by Iwama et al. ${ }^{16}$ for the Brazilian population, based on the same age range and a sample of 134 subjects, explained only $30 \%$ of the variation in the 6MWD. Dourado et al. ${ }^{17}$ also found similar results, explaining $54.3 \%$ of the $6 \mathrm{MWD}$ variance in a model based on the age, weight, height, and gender of 90 healthy adults, not including young subjects. Based on 132 volunteers (also 20-80 years of age) better distributed using the adjusted quadratic model, Soares and Pereira ${ }^{15}$ proposed a model based on height, age, and BMI and explained $55 \%$ of the variance in the 6MWD.

Despite a larger sample, our first equation, based only on anthropometric and demographic data, explained $46 \%$ of the variance. This relatively low coefficient of determination can be partially explained by the difference in anthropometric variables between different regions included in the study, without difference between 6MWD values. On the other hand, Equation 2 (including HR) explained $62 \%$ of the variance in the $6 \mathrm{MWD}$, well above the previous equations. Despite the fact that this physiological variable is a result of the work performed in the test, it can contribute to the understanding of the expected performance for individuals with different anthropometric characteristics and, particularly, in different age ranges. Thus, at present, Equation 2 seems to stand out as superior (i.e. has fewer limitations) for accurately predicting the 6MWD for Brazilians.

The 6MWT is frequently used in physical therapy routine. The ATS recommends the assessment of HR during the test. In this way, the use of Equation 2 could help determine whether changes in the 6MWD are also related to intrinsic motivation, which is an open field of investigation in regard to self-paced tests.

Given that $38.4 \%$ (Equation 2) and $53.5 \%$ (Equation 1) of the variance could not be explained 
by these models, future studies could explore the contribution of other behavioral and/or physiologic factors. The repeatability of the 6MWT with the same subject in a sequence of days could contribute to evaluate the influence of HR and intrinsic motivation behavior on 6MWD variation. It would be also interesting to assess the subjects' level of physical activity. This information could be evaluated as an independent variable and/or used to better identify the subjects' HR response.

\section{Limitation}

Although this was a multicenter study, the sample was not randomized. However, we evaluated volunteers from different centers, which can, at least in part, guarantee the diversification of the sample.

\section{Conclusion}

In summary, the present study showed that the distance covered during six minutes can be better explained and predicted when considering the HR changes during the test in addition to the anthropometric parameters. Furthermore, we have proposed two new reference equations, one of them including the heart rate changes during the test. These equations, especially the second, seem to be adequate to accurately predict the 6MWD for Brazilians.

\section{Acknowledgments}

The authors would like to thank the undergraduate students who helped with data collection and Conselho Nacional de Desenvolvimento Científico e Tecnológico-CNPq, Brazil (process 77137/2008-3) and Fundação de Amparo a Pesquisa do Estado de Minas Gerais-FAPEMIG, Brazil (PPM00072-09) for their financial support.

\section{References}

1. ATS Committee on Proficiency Standards for Clinical Pulmonary Function Laboratories. ATS statement: guidelines for the six-minute walk test. Am J Respir Crit Care Med. 2002;166(1):111-7. PMid:12091180. http:// dx.doi.org/10.1164/ajrccm.166.1.at1102

2. Troosters T, Gosselink R, Decramer Ml. Six minute walking distance in healthy elderly subjects. Eur Respir J. 1999;14(2):270-4. PMid:10515400. http://dx.doi. org/10.1034/j.1399-3003.1999.14b06.x

3. Simões LA, Dias JM, Marinho KC, Pinto CL, Britto RR. Relationship between functional capacity assessed by walking test and respiratory and lower limb muscle function in community-dwelling elders. Rev Bras
Fisioter. 2010;14(1):24-30. PMid:20414558. http://dx.doi. org/10.1590/S1413-35552010000100005

4. Puhan MA, Mador MJ, Held U, Goldstein R, Guyatt GH, Schünemann HJ. Interpretation of treatment changes in 6-minute walk distance in patients with COPD. Eur Respir J. 2008;32(3):637-43. PMid:18550610. http://dx.doi. org/10.1183/09031936.00140507

5. Poulain M, Durand F, Palomba B, Ceugniet F, Desplan J, Varray A, et al. 6-minute walk testing is more sensitive than maximal incremental cycle testing for detecting oxygen desaturation in patients with COPD. Chest. 2003;123(5):1401-7. PMid:12740254. http://dx.doi. org/10.1378/chest.123.5.1401

6. Pinto-Plata VM, Cote C, Cabral H, Taylor J, Celli BR. The 6-min walk distance: change over time and value as a predictor of survival in severe COPD. Eur Respir J. 2004;23(1):28-33. PMid:14738227. http://dx.doi.org/10. 1183/09031936.03.00034603

7. Cote CG, Casanova C, Marín JM, Lopez MV, PintoPlata V, De Oca MM, et al. Validation and comparison of reference equations for the 6-min walk distance test. Eur Respir J. 2008;31(3):571-8. PMid:17989117. http://dx.doi. org/10.1183/09031936.00104507

8. Cote CG, Pinto-Plata V, Kasprzyk K, Dordelly LJ, Celli BR. The 6-min walk distance, peak oxygen uptake, and mortality in COPD. Chest. 2007;132(6):1778-85. PMid:17925409. http://dx.doi.org/10.1378/chest.07-2050

9. Enright PL, Sherrill DL. Reference equations for the six-minute walk in healthy adults. Am J Respir Crit Care Med. 1998;158(5):1384-7. PMid:9817683. http://dx.doi. org/10.1164/ajrccm.158.5.9710086

10. Gibbons WJ, Fruchter N, Sloan S, Levy RD. Reference values for a multiple repetition 6-minute walk test in healthy adults older than 20 years. J Cardiopulm Rehabil. 2001;21(2):87-93. PMid:11314289. http://dx.doi. org/10.1097/00008483-200103000-00005

11. Camarri B, Eastwood PR, Cecins NM, Thompson PJ, Jenkins S. Six minute walk distance in healthy subjects aged 55-75 years. Respir Med. 2006;100(4):65865. PMid:16229997. http://dx.doi.org/10.1016/j. rmed.2005.08.003

12. Poh H, Eastwood PR, Cecins NM, Ho KT, Jenkins SC. Six-minute walk distance in healthy Singaporean adults cannot be predicted using reference equations derived from Caucasian populations. Respirology. 2006;11(2):211-6. PMid:16548908. http://dx.doi. org/10.1111/j.1440-1843.2006.00820.x

13. Chetta A, Zanini A, Pisi G, Aiello M, Tzani P, Neri $\mathrm{M}$, et al. Reference values for the 6-min walk test in healthy subjects 20-50 years old. Respir Med. 2006;100(9):1573-8. PMid:16466676. http://dx.doi. org/10.1016/j.rmed.2006.01.001

14. Alameri H, Al-Majed S, Al-Howaikan A. Six-min walk test in a healthy adult Arab population. Respir Med. 2009;103(7):1041-6. PMid:19230640. http://dx.doi. org/10.1016/j.rmed.2009.01.012

15. Soares MR, Pereira CA. Six-minute walk test: reference values for healthy adults in Brazil. J Bras Pneumol. 2001;37(5):576-83. 
16. Iwama AM, Andrade GN, Shima P, Tanni SE, Godoy I, Dourado VZ. The six-minute walk test and body weightwalk distance product in healthy Brazilian subjects. Braz J Med Biol Res. 2009;42(11):1080-5. PMid:19802464. http://dx.doi.org/10.1590/S0100-879X2009005000032

17. Dourado VZ, Vidotto MC, Guerra RL. Reference equations for the performance of healthy adults on field walking tests. J Bras Pneumol. 2011;37(5):60714. PMid:22042392. http://dx.doi.org/10.1590/ S1806-37132011000500007

18. Dourado VZ. Reference equations for the 6-minute walk test in healthy individuals. Arq Bras Cardiol. 2011;96:e128-38. http://dx.doi.org/10.1590/S0066-782X2011005000024

19. Enright PL. The six-minute walk test. Respir Care. 2003;48(8):783-5. PMid:12890299.

20. Borg GA. Psychophysical bases of perceived exertion. Med Sci Sports Exerc. 1982;14(5):377-81. PMid:7154893. http://dx.doi.org/10.1249/00005768-198205000-00012

21. Karvonen MJ, Kentala E, Mustala O. The effects of training on heart rate: a longitudinal study. Ann Méd Exper Fenn. 1957;35(3):307-15.

22. American College of Sports Medicine Position Stand. Position Stand on The Recommended Quantity and Quality of Exercise for Developing and Maintaining Cardiorespiratory and Muscular Fitness, and Flexibility in Adults. Med Sci Sports Exerc. 1998;30(6):975-91. PMid:9624661. http://dx.doi. org/10.1097/00005768-199806000-00032

23. Instituto Brasileiro de Geografia e Estatística. Sala de Imprensa. Available from: http://saladeimprensa.ibge. gov.br/noticias?view $=$ noticia\&id $=1 \&$ busca $=1 \%$ idnoti $\mathrm{ca}=1699$.
24. Pires SR, Oliveira AC, Parreira VF, Britto RR. Six-minute walk test at different ages and body mass index. Rev Bras Fisioter. 2007;11(2):147-51.

25. Casanova C, Celli BR, Barria P, Casas A, Cote C, De Torres JP, et al. The 6-min walk distance in healthy subjects: reference standards from seven countries. Eur Respir J. 2011;37(1):150-6. PMid:20525717. http://dx.doi. org/10.1183/09031936.00194909

26. Guyatt GH, Pugsley SO, Sullivan MJ, Thompson PJ, Berman L, Jones NL, et al. Effect of encouragement on walking test performance. Thorax. 1984;39(11):818 22. PMid:6505988 PMCid:PMC459930. http://dx.doi. org/10.1136/thx.39.11.818

27. Markland D, Tobin V. A modification to the behavioural regulation in exercise questionnaire to include an assessment of amotivation. J Sport Exerc Psychol. 2004;26(2):191-6.

28. Burr JF, Bredin SS, Faktor MD, Warburton DE. The 6-minute walk test as a predictor of objectively measured aerobic fitness in healthy working-aged adults. Phys Sportsmed. 2011;39(2):133-9. PMid:21673494. http:// dx.doi.org/10.3810/psm.2011.05.1904

\section{Correspondence}

\section{Raquel R. Britto}

Universidade Federal de Minas Gerais

Av. Antonio Carlos, 6627, Pampulha CEP 31270-90, Belo Horizonte, MG, Brazil e-mail: rbrito@ufmg.br 